\title{
Correction to: Optima nutrition: an allocative efficiency tool to reduce childhood stunting by better targeting of nutrition-related interventions
}

Ruth Pearson ${ }^{1,2,3^{*}+}$, Madhura Killedar ${ }^{1,2,3+}$, Janka Petravic ${ }^{1,2,3}$, Jakub J. Kakietek ${ }^{4}$, Nick Scott ${ }^{1,2,3}$, Kelsey L. Grantham ${ }^{1,2,3}$, Robyn M. Stuart ${ }^{1,3,5}$, David J. Kedziora ${ }^{1,2,3}$, Cliff C. Kerr ${ }^{1,3,6}$, Jolene Skordis-Worrall ${ }^{3,7}$, Meera Shekar ${ }^{4}$ and David P. Wilson ${ }^{1,2,3}$

\section{Correction to: BMC Public Health (2018) 18:384 DOI: 10.1186/s12889-018-5294-z}

It has been highlighted that the original manuscript [1] contains a typesetting error in the name of Meera Shekar. This had been incorrectly captured as Meera Shekhar in the original article which has since been updated.

\begin{abstract}
Author details
${ }^{1}$ Burnet Institute, Melbourne, Australia. ${ }^{2}$ Department of Epidemiology and Preventive Medicine, Monash University, Melbourne, Australia. ${ }^{3}$ Optima Consortium for Decision Science, Melbourne, Australia. ${ }^{4}$ The World Bank, ICF International, Washington D.C., USA. ${ }^{5}$ Department of Mathematical Sciences, University of Copenhagen, Copenhagen, Denmark. ${ }^{6}$ Complex Systems Group, School of Physics, University of Sydney, Sydney, Australia. ${ }^{7}$ Institute for Global Health, University College London, London, UK.
\end{abstract}

Received: 5 April 2018 Accepted: 5 April 2018

Published online: 26 April 2018

\section{Reference}

1. Pearson R, et al. Optima nutrition: an allocative efficiency tool to reduce childhood stunting by better targeting of nutrition-related interventions. BMC Public Health. 2018;18:384. https://doi.org/10.1186/s12889-018-5294-z.

\footnotetext{
* Correspondence: ruth.pearson@burnet.edu.au

${ }^{\dagger}$ Equal contributors

'Burnet Institute, Melbourne, Australia

${ }^{2}$ Department of Epidemiology and Preventive Medicine, Monash University,

Melbourne, Australia

Full list of author information is available at the end of the article
}

(c) The Author(s). 2018 Open Access This article is distributed under the terms of the Creative Commons Attribution 4.0 International License (http://creativecommons.org/licenses/by/4.0/), which permits unrestricted use, distribution, and reproduction in any medium, provided you give appropriate credit to the original author(s) and the source, provide a link to the Creative Commons license, and indicate if changes were made. The Creative Commons Public Domain Dedication waiver (http://creativecommons.org/publicdomain/zero/1.0/) applies to the data made available in this article, unless otherwise stated. 